\title{
POST-COURSE OUTCOMES OF APPRENTICESHIPS AND TRAINEESHIPS FOR PEOPLE WITH DISABILITY IN WESTERN AUSTRALIA
}

*Associate Professor Greg Lewis PhD, Executive Director, EDGE Employment Solutions, 38 Hood Street, Subiaco, Western Australia 6008, Australia. Phone: +61 89286 6600. Fax: +61 89288 6699. Email: Greg.Lewis@edge.org.au \& Adjunct Associate Professor, Centre for Research into Disability and Society, Curtin University

Stian H Thoresen PhD, Research Associate, Centre for Research into Disability and Society, Curtin Health Innovation Research Institute, Curtin University, GPO Box U1987 Perth, Western Australia 6845, Australia. Phone: +61 89266 3745. Fax: +61 89266 3636. Email: S.Thoresen@curtin.edu.au.

Professor Errol Cocks PhD, Director, Centre for Research into Disability and Society, Curtin Health Innovation Research Institute, Curtin University, GPO Box U1987 Perth, Western Australia 6845, Australia. Phone: +61 89266 3621. Fax: +61 89266 3636. Email: E.Cocks@curtin.edu.au.

*Corresponding author 


\section{Abstract}

Whilst the literature consistently argues that vocational education and training, including apprenticeships and traineeships, contribute to positive employment outcomes for people with disability, little is documented regarding their post-course outcomes, particularly over time. This paper presents a retrospective outcome analysis of 253 apprentices and trainees with disability who were placed and supported by EDGE Employment Solutions (EDGE) between 2000 and 2010. EDGE, established in 1984 as a Disability Employment Service (DES) in Perth, Western Australia, has actively pursued apprenticeships and traineeship for people with disability in Australia since the 1990s. Post-course outcomes, including income, hours worked, and job durability, were analysed and compared with matched pairs of current EDGE registrants with similar socio-demographic characteristics who had not commenced an apprenticeship or traineeship.

The retrospective outcome analysis found significantly better post-training outcomes for participants in the "completed” apprenticeship cohort than those achieved by their matched pairs. Improved outcomes were evident in higher hourly wages, more hours worked per week, higher weekly wages, and greater job durability. Better outcomes were also achieved by participants in the "completed” traineeship cohort and "did not complete” apprenticeship cohort. The outcomes for participants in the "did not complete" traineeship cohort did not differ significantly from the comparison group on most outcome measures. 


\section{Introduction}

EDGE is one of the largest Disability Employment Services (DES) in Australia. Since its establishment in 1984, EDGE has secured over 5,000 award (prevailing) wage jobs for more than 2,000 job seekers with intellectual, sensory, physical, neurological, and psychiatric disability throughout metropolitan Perth in Western Australia. DES receive Australian Government funding to assist job seekers with profound or severe disability, defined as 'sometimes or always requiring assistance with at least one of the core activities of communication, mobility or self-care’ [2-5]. Profound or severe disability in the Australian context is consistent with the International Classification of Functioning, Disability and Health [40], and should not be confused with what the American Association on Intellectual and Developmental Disabilities previously referred to as severe or profound mental retardation (but in the context of this article, research participants are likely to include people from the former borderline, mild, and moderate mental retardation classifications) [12]. Apprenticeships and traineeships, collectively referred to as Australian Apprenticeships in Australia, are specific courses of training reflecting 'workplace performance' and 'nationally endorsed’ industry and business standards. A typical apprenticeship or traineeship will comprise $80 \%$ paid work and $20 \%$ unpaid study. On successful course completion, apprentices and trainees will receive a certificate, rated I through IV. While there are a range of apprenticeships and traineeships, most traineeships have one to two year course durations and will lead to a certificate I or II, while most apprenticeships have three to four year course durations and will lead to a certificate III or IV. Apprenticeships and traineeships are offered in the traditional trades, and more recently, courses have also been developed in business, retail, hospitality, community services, and industry [7, 25, 29]. Currently, more than 600 distinct apprenticeships and traineeships are offered across 17 areas or industries in Western Australia [18-19]. 
Since the late 1990s, EDGE has had a strategic goal to place and support at least $10 \%$ of its job seekers in apprenticeships and traineeships, compared with the general workforce participation rate of 3.8\% [32]. This strategy has been driven by several key assumptions and understandings. First, employment opportunities for people without formal qualifications will become increasingly limited to menial, casualized, low paid positions with poor job and income security and few professional development opportunities [25]. Second, for people with intellectual or learning disability, the majority of people supported by EDGE, transfer of training from one setting (e.g., classroom) to another setting (e.g., workplace) is a particular impediment because of difficulties in generalisation of skills. Combining the workplace and the classroom is deeply embedded in apprenticeship and traineeship systems around the world. Third, the Australian Government defines long-term employment as 26 weeks. Both its generic and its disability employment contracts with non-government employment providers (such as EDGE) carry significant milestone payments to providers who assist a person to secure and retain employment for that period of time. Given that the average apprenticeship takes three years to complete and the average traineeship one year to complete, such placements serve an additional purpose of achieving long term employment benchmarks in the course of the apprenticeship or traineeship.

Vocational education and training (VET), including apprenticeships and traineeships, as well as other work-based learning programs, have been identified as positive employment pathways for people with disability. Apprentices and trainees with disability are as likely to be employed upon successful completion of their courses as their peers [9]. However, Australian and international research consistently indicated that people with disability were significantly underrepresented in VET $[8,23,38]$ and even more so in apprenticeships and traineeships. Furthermore, course completion rates were significantly lower for apprentices and trainees with disability compared to their peers [9-11, 38]. 
For people with disability, open employment, has been linked with psychological wellbeing [22]; increased social and community integration [24]; increased self-esteem [13, 15, 22]; increased social skills [13]; and increased quality of life [16, 24]. However, people with disability face multiple challenges when seeking open employment, including discrimination, prejudice and inaccurate perceptions of their work capacities [20, 26-27]. Not surprisingly, people with disability are over-represented among the unemployed [4, 13-14, 20-21, 35]. Reduced access to open employment and limitations of social security in many countries have led to a high risk poverty for people with disability [34-35]. The National Centre for Vocational Education Research (NCVER) published a range of Australian statistics through which it is possible to estimate completion rates. Reviewing apprenticeship and traineeship data in the twelve months to December 2009, it can be estimated that the completion rates for apprentices and trainees with and without disability were $50.0 \%$ and $56.7 \%$ respectively [33]. More accurate completion rates can be obtained by following specific cohorts. Combined completion rates for apprentices and trainees were estimated to be $48.4 \%$ for the 2002 cohort and $48.5 \%$ for the 2003 cohort [30]. Completion rates for all apprentices at $42.1 \%$ and $46.1 \%$ for all trainees have been estimated for 1998/1999 [10].

A recent study by NCVER [31] utilised a slightly different method of calculating the completion rates of apprentices and trainees. Persons who withdrew from an apprenticeship or traineeship, but re-enrolled in the same course within the time period of the original course, were excluded from the sample. This approach, which is identical to that used to calculate completion rates presented in this paper, calculated a combined completion rate of 61.6\% from April to June 2009.

A previously published paper described a series of local and national Australian projects documenting strategies utilized by EDGE to place and support apprentices and trainees with 
disability [25]. This paper examines employment-related outcomes of successful course completions by comparing groups of registrants who completed or did not complete apprenticeships or traineeships, and a comparison, matched-pairs group.

\section{Methods}

Data were extracted from an electronic database (ED) of all registrants maintained by EDGE. The study cohorts, covering a ten-year period from January 2000 to June 2010, comprised the groups described in section 2.3: Apprenticeship and traineeship completers, course noncompleters, and the matched-pairs group of registrants who never enrolled. Three outcome variables were calculated for each group to enable retrospective comparisons to be made.

1. Post-training wages.

2. Hours worked.

3. Job durability.

\subsection{Data extraction}

The ED is a customised modification of Microsoft Dynamics Customer Relationship Manager (MDCRM). The information collected in the ED enabled the compilation of reports mandated by government for DES in Australia. Information stored in the ED includes registrants’ employment history, hours worked and wages: which can be cross-referenced to disability classification, socio-demographic characteristics, employers, reason for deregistration, vocational education and training, and personal characteristics. Additional information stored in the ED includes registrants’ mode of transport, support network, funding, and referral sources. When registering with EDGE, job seekers formally consent to this information being recorded and utilised by EDGE in job searching, government mandated reporting, and for research purposes. Additional consent is required for publicising identifiable material. 
Data extracted from ED were analysed using both MS Excel 2007 and SPSS 17. Raw data were exported from the ED into Excel and from Excel into SPSS. Excel was utilised to identify the comparison group through random selection of a subset of all EDGE registrants who have never completed or withdrawn from an apprenticeship or traineeship. Calculations of the outcome variables, described below, also took place in Excel. Frequencies, averages, spread, and significance were generated in SPSS.

\subsection{Outcome variables}

Post-training wages are the hourly and weekly wages of participants in the apprenticeships and traineeships cohorts, for both completers and those who withdrew from their training courses. To enable comparisons across different time periods, wages have been indexed according to the OECD Main Economic Indicator dataset [36]. For participants in the apprenticeship and traineeship cohorts, mean hourly and weekly wages for the entire postcourse completion/withdrawal period were calculated. The hourly and weekly wages for the comparison group refer to mean hourly and weekly wages for the entire period registered with EDGE.

Hours worked are the mean hours worked when employed post-course completion/withdrawal in the apprenticeship and traineeship cohorts and the mean hours worked when employed in the comparison group.

Job durability is a combination of time employed and percentage of time employed. Time employed is total number of weeks employed and total percentage of time employed is total time employed divided by total time registered. Job durability includes in-training employment for the apprentice and trainee cohorts.

\subsection{Participants}

A total of 506 participant records were drawn from five groups:

1. 35 EDGE registrants who completed an apprenticeship. 
2. 94 EDGE registrants who completed a traineeship.

3. 54 EDGE registrants who began but did not complete an apprenticeship.

4. 70 EDGE registrants who began but did not complete a traineeship.

5. 253 EDGE registrants who did not commence an apprenticeship or traineeship. The first four groups included the entire cohort of EDGE registrants who enrolled in an apprenticeship or traineeship between 2000 and 2010. The comparison group comprised matched pairs of the first four groups.

The comparison group was formed by matching each participant from the first four groups with EDGE registrants with similar socio-demographic characteristics. Matching took place following a computer generated search in Excel according to the following criteria:

- Same gender.

- $\quad$ Same disability group (see table 1 ).

- First job-start within two years prior or post completion/withdrawal.

- Age within five years of the apprentice or trainee.

Time of first job-start referred to date of first post-training job for the first four groups, matched to date of first job-start for participants in the comparison group. For participants in the first four groups who de-registered with EDGE prior to obtaining post-training employment, registration date was used as the reference point, matched with registration date of participants in the comparison group. An exception to the age match was for participants aged 21 years or younger, where matches had to be within one year ${ }^{1}$. This is pertinent due to the junior wage system in Australia, described in the discussion section.

If more than one EDGE registrant met the above matching criteria, the participant for the comparison group was randomly selected in Excel. If no EDGE registrant met these criteria, the search parameters of age and first job-start/registration date were increased in increments

\footnotetext{
${ }^{1}$ For participants aged 20, the lower age band would be 19 and upper age band 25 for their match.
} 
of one year until at least one match was found. Participants were matched sequentially from group 1 through group 4 and could only be selected once. Thus, all comparison groups are mutually exclusive. An initial match, without expanding the age and first jobstart/registration bands, was found for 233 , or $92 \%$, of participants in the apprenticeship and traineeship cohorts. All participants in groups 1 through 4 were matched within a five year expansion to the bands.

\subsection{Limitations}

This study is subject to both sampling and non-sampling error. Sampling error occurs if participants randomly selected for the comparison group do not reflect the characteristics of the entire population. The stratification or matching criteria may have mitigated sampling error. Non-sampling errors may have taken place in the data extraction from ED if there were inaccurate registrant records or inconsistencies. Due to different government reporting criteria, the data available differed slightly over the decade covered in this article. From 2009 until early 2010, EDGE recorded and reported actual number of hours registrants worked, while for other time periods this article relies on employment hours stipulated in registrants' contracts. While there are likely to be some discrepancies between contracted and actual hours worked for registrants, the impact on the findings reported later are negligible as this inconsistency also carried through to the comparison sample.

\section{Findings}

Table 1 outlines the demographic characteristics of the 506 participants in this study in the five subgroups. There are more male than female participants, although this is a general characteristic of the apprentice and trainee populations, [33] and people supported by DES [5]. The higher mean age for the cohorts completing their courses relative to the cohorts who did not complete their courses is a reflection of the course duration to completion. The high 
proportion of participants with intellectual/learning disability is a reflection of the historical and current emphasis placed on this disability group by EDGE.

The following sub-sections outline completion rates, a combined account of wages and hours worked as these are interrelated, and indicators of job durability. Statistical significance was ascertained by assuming a Student's t-distribution and conducting (paired samples) Student ttests. One-way ANOVA analysis of the differences between the pairs as dependent variables in SPSS was also carried out.

\section{INSERT TABLE 1 ABOUT HERE}

\subsection{Completion rates}

Table 2 accounts for the apprenticeship and traineeship courses. There are 35 participants in the "completed” apprenticeship cohort, 94 in the "completed” traineeship cohort, 54 in the “did not complete” apprenticeship cohort, and 70 in the "did not complete” traineeship cohort. Apprentices had a completion rate of 39\% and trainees had a completion rate of 57\%. The aggregated completion rate was 51\% for all apprentices and trainees with disability. Completion rates were observed to have continually improved over the course of the decade covered in this study. This suggests that EDGE became progressively more adept at matching apprenticeships or traineeships to job seekers, providing on-the-job support and liaising with training providers [25].

Recognising the limitations due to small numbers of participants in some of the disability classifications, completion rates of participants with acquired brain injury (67\%) and sensory disabilities (63\%) were above average, while participants with psychiatric disability had a below average completion rate (33\%). 
Acknowledging the small number of participants in several of the training courses, participants in Arts, Sports \& Recreation (60\%); Building and Construction (57\%); Electrical (100\%); Finance, Property \& Business Services (71\%); Primary Industry (61\%); and Transport \& Storage (100\%) apprenticeships and traineeships had above average completion rates. In contrast, participants in Automotive (35\%); Hospitality \& Tourism (38\%); Light Manufacturing (33\%); Process Manufacturing (0\%); and Wholesale, Retail \& Personal Services (35\%) apprenticeships and traineeships had below average completion rates.

\section{INSERT TABLE 2 ABOUT HERE}

\subsection{Wages and hours worked}

Tables 3 and 4 outline wages and hours worked across the five cohorts. Participants' wages are reported in Australian dollars. On January 4, 2011, the exchange rate was 1AUD = 1.0099USD [37].

The mean hourly wage of $\$ 18.17$ for participants who completed their apprenticeship is $\$ 3.40$ higher than for their matched pairs $(\mathrm{t}(22)=2.73, \mathrm{p}<.01)$. The hourly wage differences between the other cohorts were not statistically significant.

Mean weekly hours are:

- 35\% higher for the "completed" apprenticeship cohort than their matched pairs ( $\mathrm{t}(22)$ $=3.29, \mathrm{p}<.005)$.

- $\quad 28 \%$ higher for the "completed” traineeship cohort than their matched pairs $(\mathrm{t}(78)=$ 4.10, $\mathrm{p}<.001)$.

- $\quad 48 \%$ higher for the "did not complete” apprenticeship cohort than their matched pairs $(\mathrm{t}(29)=4.30, \mathrm{p}<.001)$. 
- $\quad 4 \%$ higher for the “did not complete traineeship” cohort than their matched pairs (no statistical significance).

The mean weekly wage is:

- $11 \%$ higher for the "completed” apprenticeship cohort than their matched pairs ( $\mathrm{t}(22)$ $=4.27, \mathrm{p}<.001)$.

- $\quad 27 \%$ lower for the "completed” traineeships than their matched pairs $(\mathrm{t}(78)=2.40$, $\mathrm{p}$ $<.01)$

- $\quad 61 \%$ higher for the "did not complete” apprenticeship cohort than their matched pairs $(\mathrm{t}(29)=3.76, \mathrm{p}<.001)$

- $3 \%$ lower for the "did not complete" traineeships cohort than their matched pairs (no statistical significance).

The one-way ANOVA analysis of the difference between the pairs indicated weak significance for the difference in hourly wage $(F(3,163)=2.41, \mathrm{p}<.069)$ but strong significance for the difference in weekly hours $(F(3,163)=4.40, \mathrm{p}<.005)$ and weekly wage $(\mathrm{F}(3,163)=5.90, \mathrm{p}<.001)$

\section{INSERT TABLES 3 \&4 ABOUT HERE}

The latest available data on differentiated income levels according to disability status in Australia indicated that median gross weekly income for working-aged people (15-64 years) with a disability was \$255 compared with \$501 for working-aged people without disability. The median gross weekly income for working-aged people with profound and severe disability was lower at $\$ 200$ and $\$ 212$ respectively [1]. Adjusting these figures in accordance with the OECD Main Economic Indicator set, the comparable median income for working- 
aged people with disability in Australia is \$313.52 and \$615.97 for working-aged people without disability.

These figures reflected gross weekly income and included government allowances and pensions, such as the Disability Support Pension. Study participants, particularly when unemployed, on low hourly rates, or with low weekly hours, were eligible for a range of government income support which has not been recorded in this study. The median weekly wage of study participants were:

- $143 \%$ higher for the "complete” apprenticeship cohort than for working-age people with disability and 25\% greater than the general population.

- $\quad 25 \%$ higher for the "completed” traineeship cohort than for working-aged people with disability but $24 \%$ lower than the general population.

- $\quad 70 \%$ higher for the “did not complete” apprenticeship cohort than for working-aged people with disability but $13 \%$ lower than the general population.

- $6 \%$ higher for the "did not complete” traineeship cohort than for working-aged people with disability but $46 \%$ lower than the general population.

An NCVER study of apprentices and trainees nine months after course completion/withdrawal found that completers who were working full-time were on average earning \$924.38 a week when surveyed between March and May 2010 [31]. Non-completers working full-time were on average earning \$780.55. These incomes are higher than the mean and median weekly wages of study participants. However, when including only participants working 35 hours or more a week, the mean weekly wage is:

- $\quad \$ 822.65$ for the “completed” apprenticeship cohort $(n=22)$ - 11\% lower than for their non-disabled peers.

- $\quad$ \$633.61 for the “completed” traineeship cohort $(n=38)$ - 31\% lower than their nondisabled peers. 
- \$599.07 for the “did not complete” apprenticeship cohort (n=15) - 23\% lower than their non-disabled peers.

- $\quad \$ 684.81$ for the “did not complete” traineeship cohort (n=11) - 12\% lower than their non-disabled peers.

In comparison, the median income for working-aged people with disability is $49 \%$ lower than their non-disabled peers.

Undertaking apprenticeships and traineeships appears to be a powerful equalising factor by significantly reducing the pay inequity between the two groups - even for participants who do not complete their courses.

\subsection{Job durability}

Table 5 outlines the number of weeks employed, registered, and percentage of time employed across the five cohorts.

Mean weeks employed are:

- $\quad$ 87\% higher for the “completed” apprenticeship cohort than their matched pairs (t(34) $=8.43, \mathrm{p}<.001)$

- $148 \%$ higher for the "completed" traineeship cohort than their matched pairs $(\mathrm{t}(93)=$ 6.56, $\mathrm{p}<.001)$

- $71 \%$ higher for the "did not complete” apprenticeship cohort than their matched pairs $(\mathrm{t}(53)=3.05, \mathrm{p}<.005)$

- $\quad 98 \%$ higher for the "did not complete” traineeship cohort than their matched pairs

$$
(\mathrm{t}(69)=3.87, \mathrm{p}<.001)
$$

Mean percentage of time employed is:

- $179 \%$ higher for the “completed” apprenticeship cohort than their matched pairs

$$
(t(34)=10.14, p<.001)
$$


- $52 \%$ higher for the "completed" traineeship cohort than their matched pairs $(\mathrm{t}(34)=$ 7.13, $\mathrm{p}<.001)$.

- $90 \%$ higher for the "did not complete” apprenticeship cohort than their matched pairs $(\mathrm{t}(53)=5.18, \mathrm{p}<.001)$

- $104 \%$ higher for the "did not complete" traineeship cohort than their matched pairs $(\mathrm{t}(69)=6.24, \mathrm{p}<.001)$

The one-way ANOVA analysis of the difference between the pairs indicated strong significance for the difference in number of weeks employed $(F(3,163)=7.65, p<.001)$ and percentage time employed $(F(3,163)=7.06, \mathrm{p}<.001)$.

\section{INSERT TABLE 5 ABOUT HERE}

High job durability for people undertaking apprenticeships and traineeships is consistent with findings from NCVER which indicated that $90.1 \%$ of completers and $73.4 \%$ of noncompleters were employed when surveyed nine months post-completion/course withdrawal [31].

Anecdotal evidence suggested that many EDGE registrants who completed apprenticeships and traineeships became independent workers and de-registered for that reason. Among the study participants in the apprenticeship or traineeship cohort, 105 or $42 \%$ de-registered within nine months of course completion/withdrawal. Accounting only for post-training outcomes for participants in the apprenticeship and traineeship cohorts who remained registered with EDGE for nine months or longer post-training:

- $88 \%$ in the "completed” apprenticeship cohort obtained post-training employment.

- $\quad 97 \%$ in the “completed” traineeship cohort obtained post-training employment. 
- $97 \%$ of participants in the "did not complete" apprenticeship cohort obtained posttraining employment.

- $91 \%$ of participants in the "did not complete" traineeship cohort obtained posttraining employment.

\section{Discussion}

There is a junior wage system in Western Australia. The minimum hourly wage for adults age 21 years or older was $\$ 14.99$ as of June 30, 2010. Persons 20 years of age are entitled to $90 \%$ of the full wage; $80 \%$ for 19 year olds; $70 \%$ for 18 year olds; $60 \%$ for 17 year olds; $50 \%$ for 16 year olds; and $40 \%$ for those aged under 16 years [17]. It is probable that the junior wage system has impacted the wages for participants in the "did not complete" traineeship cohort which had a mean age of 19.2 years and, to a lesser extent, the comparison group which had a mean age of 20.5 years. Acknowledging this caveat, completing and undertaking apprenticeships and traineeships appears to have an equalising effect on weekly income for people with disability relative to their non-disabled peers. The mean weekly wages of participants working full-time in the apprenticeship and traineeship cohorts with disability in this study were 11\%-31\% lower than their peers from an NCVER study [31]. In comparison, mean income for working-age Australians with a profound disability is $63 \%$ lower and $61 \%$ lower for people with a severe disability than their non-disabled peers [4]. Increased equity in income may reflect an increased employability of participants in the apprenticeship and traineeship cohorts. Having been accepted as an apprentice or trainee reflected job-readiness, more so for participants who completed their training courses. While only participants in the "completed" apprenticeship cohort had a statistically significant higher hourly wage than the comparison group, the mean weekly wage for participants in the "completed" traineeship and "did not complete" apprenticeship cohorts is higher due to the higher mean weekly hours relative to the comparison group. 
The findings from this study clearly indicate better post-training outcomes for participants who complete apprenticeships. The similar post-training outcomes for participants in the “completed” traineeship and “did not complete” apprenticeship cohorts are interesting. The mean hourly wage is greater for the "completed” traineeship than the "did not complete" apprenticeship cohort (although not statistically significant), while the mean number of weekly hours is greater for the "did not complete" apprenticeship cohort than for the “completed" traineeship cohort $(\mathrm{p}<.15)$. The mean weekly wage is slightly higher for the “did not complete” apprenticeship cohort than for the "completed” traineeship cohort (although not statistically significant). Thus it can be argued that commencing, but not completing, apprenticeships has the same post-training value as completing a traineeship for the participants in this study. This may reflect employability associated with having been an apprentice, despite withdrawing from the course. This is particularly pertinent as apprenticeships comprise on average three years work-based training and employment compared with a one year average duration for traineeships. Participants who "did not complete” apprenticeships obtain more weekly hours of employment than participants who “completed” traineeships.

The job durability variable indicated better progressive outcomes across the apprenticeship and traineeship cohorts, both regarding mean number of weeks employed and percentage time employed. This could be considered as both an intrinsic variable (i.e., arising from the nature of the course) as well as an outcome variable as the job durability measure includes intraining and post-course completion/withdrawal employment for the apprenticeship and traineeship cohorts. Progressively improving job durability across the training hierarchy (comparison group, “did not complete” traineeship, “did not complete” apprenticeship, “completed” traineeship, and “completed” apprenticeship) also reflects the impact of the intraining element of job durability. This was also a strong rationale for placing and supporting 
people with disability in apprenticeships and traineeships. In essence, the means and the end (durable employment) were one in the same. This is also reflected in the significant support apprentices and trainees receive from EDGE in-training which may contribute to their improved post-training outcomes. On average, apprentices and trainees receive about 70 hours of active support from EDGE in a calendar year.

This study did not fully capture post-training job durability due to the large number of participants in the apprenticeship and traineeship cohorts who de-registered shortly after course completion/withdrawal (42\% within nine months).

A recent Australian survey indicated that even those employers who are positive about hiring people with disability are uncertain of their own capacities and capabilities to support an employee with disability and are generally unaware of supports available [39]. As outlined above, post-training employment outcomes of the apprenticeship and traineeship cohorts in this study were significantly better than the general population. DES support during training and exposure to workplace expectations as apprentices and trainees contributed to positive post-course completion/withdrawal employment outcomes. This may be have been influenced by professional and social relationships developed in the workplace, recognised skills acquired in the workplace, a stable work history, the development of a professional identity and a clear career pathway.

\section{Conclusion}

The findings of this study strongly indicated that participants who completed apprenticeships obtained significantly better post-training outcomes than the other apprenticeship and traineeship cohorts and the comparison group. Participants in the "completed” traineeship and “did not complete” traineeship cohorts also obtained better post-training outcomes relative to the comparison group. Participants in the "did not complete" traineeship cohort did not have statistically significant different post-training outcomes than the comparison group. There is 
also intrinsic value in undertaking an apprenticeship or traineeship which, in itself, delivers increased job durability.

The attractiveness of work-based apprenticeships and traineeships relate to both the intraining benefits as well as post-training outcomes. While in training, apprentices and trainees learn a vocation, are exposed to workplace expectations, fulfil a valued social role as a worker, establish social relationships with co-workers, and obtain a nationally recognised qualification when successfully completing their courses.

The authors propose to investigate further the economic and social outcomes of apprenticeships and traineeships for people with disability. A three-year longitudinal study of 300 apprentices and trainees in Australia, of whom 80\% have an identified disability, will be commenced in 2011. This prospective study will investigate the relationship between completing apprenticeships and traineeships and social outcomes such as social inclusion, quality of life, post-training employment, hourly and weekly wages, and job durability.

\section{Acknowledgements}

The authors would like to acknowledge the contributions of Richard Parsons in the statistical modelling for this article. The authors would also like to acknowledge the contributions of EDGE staff in compiling data from the ED for this article. 


\section{References}

[1] Australian Bureau of Statistics, Australian demographic statistics, Dec 2003 (2004), http://www.abs.gov.au/AUSSTATS/abs@.nsf/Previousproducts/3101.0Main\%20Features1D ec\%202003?opendocument\&tabname=Summary\&prodno=3101.0\&issue=Dec\%202003\&nu $\mathrm{m}=$ \&view=, retrieved January 19, 2010.

[2] Australian Bureau of Statistics, Disability, Australia 2009. ABS cat. no. 4446.0, Canberra: ABS, 2011.

[3] Australian Bureau of Statistics, Disability, ageing and carers Australia: summary of findings, 2009. ABS cat. no 4430.0, Canberra: ABS 2010.

[4] Australian Bureau of Statistics, Disability, ageing and carers, Australia: summary of findings, 2003. ABS cat. no. 4430.0, Canberra: ABS, 2004.

[5] Australian Institue of Health and Welfare, Disability support services 2008-09: report on services provided under the Commonwealth State/Territory disability agreement and the national disability agreement. Disability series. Cat. no. DIS 58, Canberra: AIHW, 2011. [6] Australian Institute of Health and Welfare, Australia's welfare 2009, Canberra: AIHW, 2009.

[7] Australian Qualifications Framework Advisory Board, Australian qualification framework: implementation handbook (4 ${ }^{\text {th }}$ Edition), Carlton South: AQF Advisory Board, 2007.

[8] M. Bagshaw \& C. Fowler, National VET disability advisory taskforce: final report and recommendations, Department of Education, Employment and Workplace Relations, 2008. [9] K. Ball, Outcomes for people with a disability in vocational education and training, Pathways 5 national conference: Reviewing the past - adapting to the future, Canberra 6-8 December 2000, http://www.adcet.edu.au/StoredFile.aspx?id=1331\&fn=Ball.pdf, retrived November 18, 2009. 
[10] K. Ball, Factors influencing completion of apprenticeships and traineeships, Australian Labour Market Research Workshop, Perth 6-7 December 2004, http://www.ncver.edu.au/pubs/confs/KBall_ALMRW2004.pdf, retrived November 18, 2009. [11] K. Ball and J. David, Apprentice and trainee completion rates, Adelaide: NCVER, 2005. [12] M. J. Begab, D. Cantwell, J. D Clements, R. Eyman, C. E Meyers, G. Tarjan and S. A. Warran, Manual on terminology and classification in mental retardation, H. J Grossman (Ed.), Washington, D.C.: American Association on Mental Deficiency, 1977.

[13] M. Corbiere and T. Lecomte, Vocational services offered to people with severe mental illness, Journal of Mental Health, 18(1) (2009), 38-50.

[14] R. E. Crowther, M. Marshall, G. R. Bond and P. Huxley, Helping people with severe mental illness to obtain work: a systematic review, British Medical Journal, 322(27 January) (2001), 204-208.

[15] R. M. Dixon and C. Reddacliff, Family contribution to the vocational lives of vocationally competent young adults with intellectual disabilities, International Journal of Disability, Development and Education, 48(2) (2001), 193-206.

[16] I. Eggleton, S. Robertson, J. Ryan and R. Kober, The impact of employment on the quality of life of people with an intellectual disability. Journal of Vocational Rehabilitation, (13) (1999), 95-107.

[17] Government of Western Australia, Western Australian minimum wage rates 2000-2009 (n.d.), http://www.commerce.wa.gov.au/LabourRelations/PDF/Awards/M/PreviousStateminimumw agerates.pdf, retrived January 10, 2010.

[18] Government of Western Australia, Department of Training and Workforce Development, Western Australian apprenticeships list (2011), http://www.trainingwa.wa.gov.au/apprenticentre/detcms/portal/, retrieved May 10, 2011. 
[19] Government of Western Australia, Department of Training and Workforce

Development, Western Australian traineeships list (2011),

http://www.trainingwa.wa.gov.au/apprenticentre/detcms/portal/, retrieved May 10, 2011.

[20] B. Hernandez, M. J. Cometa, J. Velcoff, J. Rosen, D. Schober and R. D. Luna,

Perspectives of people with disabilities on employment, vocational rehabilitation, and the

Ticket to Work program, Journal of Vocational Rehabilitation, 27(3) (2007), 191-201.

[21] Human Rights and Equal Opportunity Commission, Issues Paper 1: Employment and disability - the statistics (2005),

http://www.hreoc.gov.au/disability_rights/employment_inquiry/docs/Issue1_statistics.pdf, retrived December 4, 2009.

[22] D. Jiranek and N. Kirby, The job satisfaction and/or psychological well being of young adults with an intellectual disability and nondisabled young adults in either sheltered employment, competitive employment or unemployment, Journal of Intellectual \& Developmental Disability, 16(2) (1990), 133-148.

[23] K. Jones, Improving participation in vocational education and training and employment for students with disabilities, Intellectual Disability Australasia, March 2005 (2005), 12-14.

[24] R. O. Kober and I. R. C. Eggleton, The effect of different types of employment on quality of life. Journal of Intellectual Disability Research, 49(10) (2005), 756-760.

[25] G. Lewis, S. H. Thoresen and E. Cocks, Successful approaches to placing and supporting apprentices and trainees with disability in Australia, Journal of Vocational Rehabilitation, 34(3) (2011), 181-189.

[26] E. P. Y Li, Self-perceived equal opportunities for people with intellectual disability. International journal of Rehabilitation Research, 27 (2004), 241-245.

[27] R. G. Luecking, Emerging employment views of people with disabilities and the future of job development, Journal of Vocational Rehabilitation, (29) (2008), 3-13. 
[28] S. Mannila, Factors influencing the disabled's employment in the competitive labour market, International journal of Rehabilitation Research, (18) (1995), 19-25.

[29] R. Naidu, VET glossary (2008), Adelaide: NCVER

http://www.ncver.edu.au/res/glossary/Glossary.pdf, retrived December 10, 2009.

[30] National Centre for Vocational Education Research, Australian vocational education and training statistics: apprentices and trainees, 2008 - annual, Adelaide: NCVER, 2009. [31] National Centre for Vocational Education Research, Apprentice \& trainee destinations: Australian vocational education \& training statistics, Adelaide: NCVER, 2010. [32] National Centre for Vocational Education Research, Australian vocational education and training statistics: apprentices and trainees - annual 2009, Adelaide: NCVER, 2010. [33] National Centre for Vocational Education Research, Students with a disability (2010), http://www.ncver.edu.au/publications/2269.html, retrieved December 8, 2010.

[34] Organisation for Economic Co-operation and Development, Transforming disability into ability: policies to promote work and income securityfor disabled people, Paris: OECD Publications, 2003.

[35] Organisation for Economic Co-operation and Development, Sickness, disability and work: breaking the barriers: vol. 2: Australia, Luxembourg, Spain and the United Kingdom, Paris: OECD Publications, 2007.

[36] Organisation for Economic Co-operation and Development, Dataset: hourly earnings (2010), http://stats.oecd.org/Index.aspx, retrieved May 27, 2010.

[37] Reserve Bank of Australia, Exchange rates (2011), http://www.rba.gov.au/statistics/frequency/exchange-rates.html, retrieved January 5, 2011. [38] C. Selby Smith and F Ferrier, Funding arrangements for VET students with a disability: more talk or actual improvement?, International Journal of Training Research, 3(2) (2005), $1-15$. 
[39] P. Waterhouse, H. Kimberley, P. Jonas and J. Glover, What would it take? employer perspectives on employing people with a disability, Adelaide: NCVER, 2010.

[40] World Health Organization, International classification of functioning, disability and health, Geneva: WHO, 2001. 
Table 1: Participants

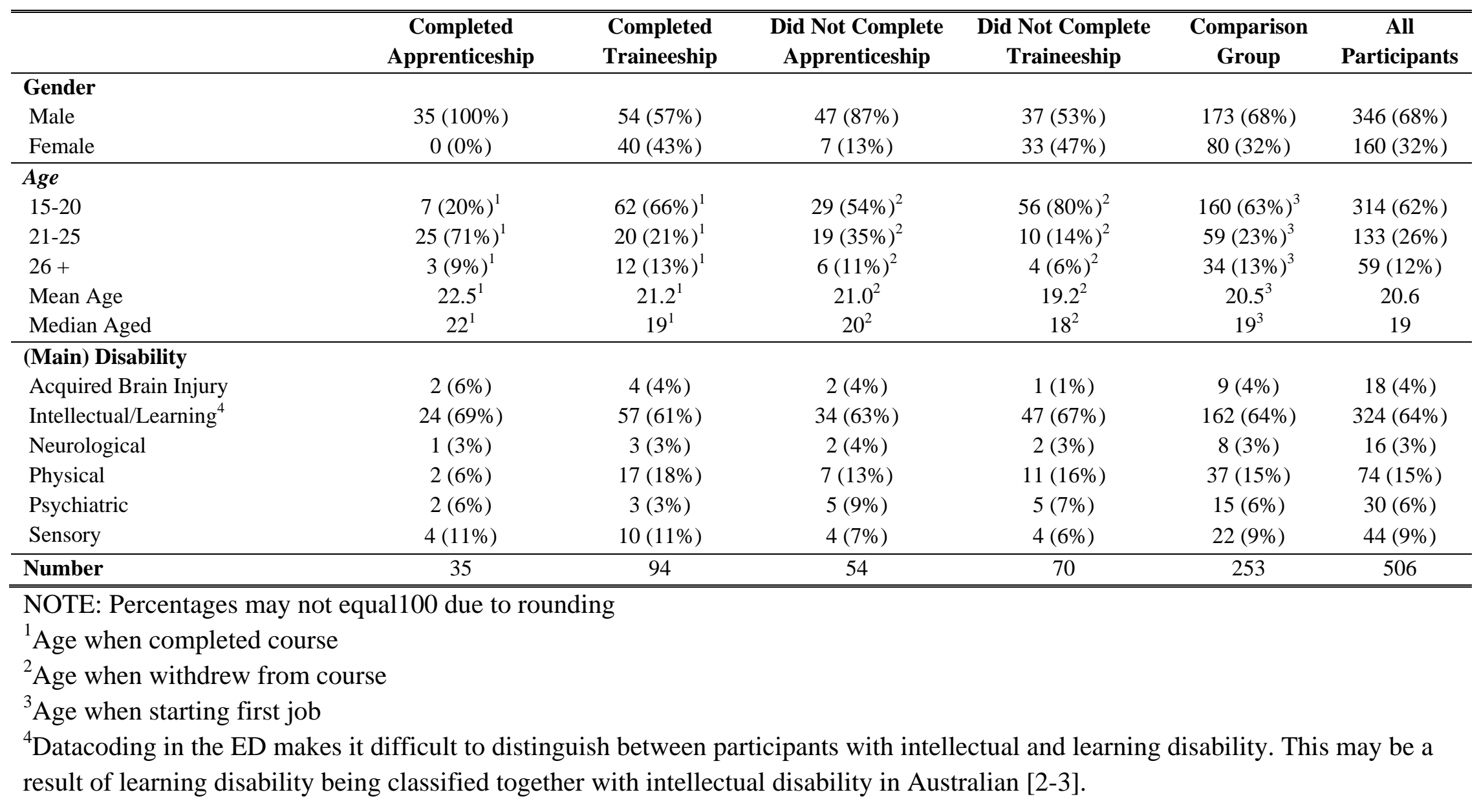


Table 2: Apprenticeship and Traineeship Courses

\begin{tabular}{|c|c|c|c|c|c|}
\hline & $\begin{array}{c}\text { Completed } \\
\text { Apprenticeship }\end{array}$ & $\begin{array}{l}\text { Completed } \\
\text { Traineeship }\end{array}$ & $\begin{array}{l}\text { Did Not Complete } \\
\text { Apprenticeship }\end{array}$ & $\begin{array}{c}\text { Did Not Complete } \\
\text { Traineeship }\end{array}$ & $\begin{array}{c}\text { All Apprentices } \\
\text { and Trainees }\end{array}$ \\
\hline Arts, Sport \& Recreation & - & $3(3 \%)$ & - & $2(3 \%)$ & $5(2 \%)$ \\
\hline Automotive & $9(26 \%)$ & $2(2 \%)$ & $15(28 \%)$ & $5(7 \%)$ & $31(12 \%)$ \\
\hline Building and Construction & $7(20 \%)$ & $1(1 \%)$ & $6(11 \%)$ & - & $14(6 \%)$ \\
\hline Community Services, Health \& Education & - & $8(9 \%)$ & $1(2 \%)$ & $6(9 \%)$ & $15(6 \%)$ \\
\hline Electrical & $1(3 \%)$ & N/A & - & N/A & $1(<1 \%)$ \\
\hline Finance, Property \& Buisness Services & N/A & $36(38 \%)$ & N/A & $15(21 \%)$ & $51(20 \%)$ \\
\hline Food & $4(11 \%)$ & $3(3 \%)$ & $5(9 \%)$ & $1(1 \%)$ & $13(5 \%)$ \\
\hline Hospitality \& Tourism & $3(9 \%)$ & $12(13 \%)$ & $9(17 \%)$ & $15(21 \%)$ & $39(15 \%)$ \\
\hline Light Manufacturing & $2(6 \%)$ & $3(3 \%)$ & $4(7 \%)$ & $6(9 \%)$ & $15(6 \%)$ \\
\hline Metals, Manufacturing \& Services & $6(17 \%)$ & $2(2 \%)$ & $6(11 \%)$ & $1(1 \%)$ & $15(6 \%)$ \\
\hline Primary Industry & $2(6 \%)$ & $9(10 \%)$ & $4(7 \%)$ & $3(4 \%)$ & $18(7 \%)$ \\
\hline Process Manufacturing & - & - & - & $1(1 \%)$ & $1(<1 \%)$ \\
\hline Transport \& Storage & N/A & $2(2 \%)$ & N/A & - & $2(1 \%)$ \\
\hline Utilities, Electrotechnology \& Printing & $1(3 \%)$ & $6(6 \%)$ & - & $6(9 \%)$ & $13(5 \%)$ \\
\hline Wholesale, Retail \& Personal Services & - & $7(7 \%)$ & $4(7 \%)$ & $9(13 \%)$ & $20(8 \%)$ \\
\hline Number & 35 & 94 & 54 & 70 & 253 \\
\hline
\end{tabular}

NOTE: Percentages may not equal100 due to rounding 
Table 3: Wages (AUD)

\begin{tabular}{|c|c|c|c|c|c|c|}
\hline & $\begin{array}{c}\text { Completed } \\
\text { Apprenticeship }\end{array}$ & $\begin{array}{l}\text { Completed } \\
\text { Traineeship }\end{array}$ & $\begin{array}{c}\text { Did Not Complete } \\
\text { Apprenticeship }\end{array}$ & $\begin{array}{c}\text { Did Not Complete } \\
\text { Traineeship }\end{array}$ & $\begin{array}{l}\text { Comparison } \\
\text { Group }\end{array}$ & $\begin{array}{c}\text { All } \\
\text { Participants }\end{array}$ \\
\hline Number & 23 & 78 & 30 & 36 & 167 & 334 \\
\hline Mean Hourly Wage & 18.17 & 14.42 & 13.74 & 13.96 & 14.10 & 14.33 \\
\hline Median Hourly Wage & 17.20 & 14.22 & 13.66 & 14.28 & 14.20 & 14.47 \\
\hline Minimum-Maximum Hourly Wage & 11.49-39.97 & $6.21-24.75$ & $6.16-20.73$ & $7.00-29.26$ & $0.53-38.27$ & $0.53-39.97$ \\
\hline Mean Weekly Wage $^{1}$ & 708 & 426 & 446 & 340 & 349 & 398 \\
\hline Median Weekly Wage $^{1}$ & 673 & 410 & 467 & 265 & 292 & 379 \\
\hline Minimum-Maximum Weekly Wage ${ }^{1}$ & $437-1,599$ & $90-928$ & $62-824$ & $88-1,097$ & $9-1,280$ & $9-1,599$ \\
\hline
\end{tabular}

${ }^{1}$ Rounded to nearest dollar 
Table 4: Hours Worked

\begin{tabular}{|c|c|c|c|c|c|c|}
\hline & $\begin{array}{c}\text { Completed } \\
\text { Apprenticeship }\end{array}$ & $\begin{array}{c}\text { Completed } \\
\text { Traineeship }\end{array}$ & $\begin{array}{c}\text { Did Not Complete } \\
\text { Apprenticeship }\end{array}$ & $\begin{array}{c}\text { Did Not Complete } \\
\text { Traineeship }\end{array}$ & $\begin{array}{c}\text { Comparison } \\
\text { Group }\end{array}$ & $\begin{array}{c}\text { All } \\
\text { Participants }\end{array}$ \\
\hline Number & 23 & 78 & 30 & 36 & 167 & 334 \\
\hline Mean Weekly Hours & 38.86 & 29.40 & 32.23 & 23.45 & 23.89 & 26.91 \\
\hline Median Weekly Hours & 38.88 & 33.73 & 35.43 & 19.55 & 20.94 & 28.90 \\
\hline Minimum-Maximum Weekly Hours & $28.41-45$ & $6.32-43.16$ & $10.00-47.59$ & $9.00-40.00$ & $6.52-63.25$ & $6.32-63.25$ \\
\hline
\end{tabular}


Table 5: Job Durability

\begin{tabular}{|c|c|c|c|c|c|c|}
\hline & $\begin{array}{c}\text { Completed } \\
\text { Apprenticeship }\end{array}$ & $\begin{array}{c}\text { Completed } \\
\text { Traineeship }\end{array}$ & $\begin{array}{c}\text { Did Not Complete } \\
\text { Apprenticeship }\end{array}$ & $\begin{array}{c}\text { Did Not Complete } \\
\text { Traineeship }\end{array}$ & $\begin{array}{c}\text { Comparison } \\
\text { Group }\end{array}$ & $\begin{array}{c}\text { All } \\
\text { Participants }\end{array}$ \\
\hline Number & 35 & 94 & 54 & 70 & 253 & 506 \\
\hline Mean Weeks Employed $^{1}$ & 277 & 209 & 149 & 101 & 73 & 124 \\
\hline Median Weeks Employed ${ }^{1}$ & 233 & 158 & 92 & 61 & 18 & 72 \\
\hline Mimimum-Maximum Weeks Employed ${ }^{1}$ & $52-858$ & $41-977$ & $3-853$ & $1-426$ & $0-519$ & $0-977$ \\
\hline Mean Weeks Registered $^{1}$ & 313 & 280 & 209 & 156 & 137 & 186 \\
\hline Median Weeks Registered $^{1}$ & 270 & 193 & 141 & 127 & 97 & 137 \\
\hline Minimum-Maximum Weeks Registered ${ }^{1}$ & $53-908$ & $62-1,211$ & $22-985$ & $13-462$ & $3-918$ & $3-1,211$ \\
\hline Mean \% Time Employed & $90 \%$ & $74 \%$ & $61 \%$ & $54 \%$ & $36 \%$ & $52 \%$ \\
\hline Median \% Time Employed & $93 \%$ & $77 \%$ & $63 \%$ & $57 \%$ & $24 \%$ & $60 \%$ \\
\hline Minimum-Maximum \% Time Employed & $28 \%-100 \%$ & $23 \%-100 \%$ & $5 \%-100 \%$ & $2 \%-99 \%$ & $0 \%-100 \%$ & $0 \%-100 \%$ \\
\hline
\end{tabular}

${ }^{1}$ Rounded to nearest week 